\title{
The Effect of Upper Cervical Manipulation on Autonomic Nervous System in Young Healthy Individuals
}

\author{
Seunggu Lee ${ }^{a}$, Yongwoo Lee ${ }^{a}$

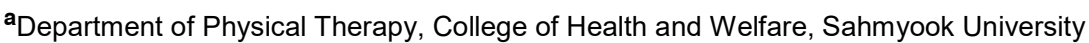

Objective: The purpose of this study was to investigate the alteration of upper cervical manipulation to autonomic nervous system (ANS) through the heart rate variability(HRV) analysis in young healthy individuals.

Design: Two-group pretest-posttest design.

Methods: Thirty four young healthy participants ( 17 males and 17 females) were randomized into the 2 groups, such as the upper cervical manipulation group (UCM group, $n=17$ ), neck stretching group (NS group, $n=17$ ). UCM group received a upper cervical manipulation, especially on the atlas, and NS group did stretch for both side of upper trapezius and levator scapular. For the UCM, Atlas mobility was checked by therapist and thrust was given once at the posterior arch of Atlas. HRV was measured before and after intervention to investigate ANS alteration. After the intervention, both groups were given 3 minutes break-time before measuring HRV.

Results: The UCM group showed significant differences in ANS Activity, Stress Resistance, Stress index and Fatigue Index (p $<0.05$ ) while no differences in NS group with before and after intervention. There were significant differences in ANS Activity, Stress Resistance, and Fatigue Index between groups $(\mathrm{p}<0.05)$.

Conclusions: This study suggected that upper cervical manipulationhas positive effects on the ANS activity, stress resistance, and fatigue index.

Key Words: Cervical manipulation, Autonomic nervous system, Parasympathetic, Sympathetic

서론

척추 가동술, 고속저진폭(HVLA) 교정, 가동화기법 (Mobilization with movement) 등은 물리치료사가 척추 통증과 움직임 장애를 치료하기 위해 사용하는 도수치료 방법 중 하나이다[1-3]. 가동술은 가동범위의 끝까지 단계 별로 적용되는 수동적이며 진동을 가하는 움직임이라고 정의할 수 있다[3]. 이러한 가동술은 환자가 제어할 수 있 는 정상가동범위 내에서 행해지는 반면 척추 교정은 환자 가 제어할 수 없는 가동범위의 끝에서 일어나는 빠른 움 직임이다[4].

척추 통증은 장애와 경제적인 부담을 초래하고 매우 많 은 사람들에게 영향을 주는 흔한 장애이다. 대략 $54-80 \%$ 의 인구가 살면서 한번쯤 척추 통증을 경험하게 된다[5].
연구에 따르면 직장에서의 신체적 정신적 요인들도 척추 통증을 유발할 수 있다고 한다. 성별, 직업, 감정의 문제, 흡연, 낮은 직업 만족도, 질 낮은 작업 환경들도 척추 통 증과 관련이 있다[6]. 척추 교정 치료들의 주 목적은 척추 통증을 감소시키고 부정렬을 바로잡기 위함이다[1]. 최근 연구에 따르면 관절가동술과 교정은 목 통증[7], 경추기원 성 두통과 어지러움증 $[8,9]$ 그리고 허리 통증에 긍정적인 임상 효과가 있다 $[10,11]$.

현재 척추교정의 임상 효과는 말초, 척수, 척수 상위 수준의 메커니즘에 의해 매개되는 것으로 여겨지고 있다. 연구 결과에 의하면 교감신경계의 활동이 척추교정에 의 한 통각저하를 유도하는 신경생리학적 사건의 연속적인 역할을 한다고 하였다[12-14]. 여러 부위의 척추 교정 중 에서도 특히 상부경추의 부정렬은 심혈관계 기능 조절 중

Received: May 28, 2021 Revised: Jun 1, 2021 Accepted: Jun 2, 2021

Corresponding author: Yongwoo Lee(ORCID https://orcid.org/0000-0001-9978-1924)

Department of Physical Therapy, College of Health and Welfare, Sahmyook University.

815, Hwarang-ro, Nowon-gu, Seoul, 01795 Republic of Korea [01795]

Tel: + 82-2-3399-1636 Fax: + 82-2-3399-1639 E-mail: yongwo2@syu.ac.kr

This is an Open-Access article distributed under the terms of the Creative Commons Attribution Non-Commercial License (http://creativecommons.org/licenses/ by-nc/4.0) which permits unrestricted non-commercial use, distribution, and reproduction in any medium, provided the original work is properly cited.

Copyright $(2021$ Korean Academy of Physical Therapy Rehabilitation Science 
추인 뇌간(Brainstem)의 신경회로를 압박하고 장애를 일 으킬 수 있다. 환추(atlas)의 해부학적 위치 변화와 연결된 회로는 추골동맥(vertebral artery)의 순환의 변화를 가져 올 수 있으며[15], 따라서 이러한 상부경추의 교정이 혈압 과 심장박동수에 영향을 줄 수 있을 것이며, 이 효과의 기 본 원리는 부교감신경의 자극을 통해서 일 것이라고 생각 된다[3]. 경추 교정은 뇌간을 통해 직접적으로 부교감신경 의 흐름을 자극하거나 척추교정을 통해 경동맥공(carotid sinus)이 자극되고 결국 고립로핵(nucleus tractus solitaries) 을 통해 뇌간이 자극되는 간접적인 방법으로 부교감신경 의 흐름을 자극할 수 있게 된다[15, 16].

경추 교정이 자율신경계에 미치는 효과에 대한 선행 연 구는 주로 교정 부위를 상부경추가 아닌 경추(C2-C7)부 위[17, 18], 혹은 흥추나[19] 요추로[20] 설정하였거나 교 정이 아닌 가동술을 중재로 선택하기도 하였다[21]. 이에 본 연구에서는 상부경추 교정이 자율신경계의 활동에 미 치는 영향을 심박변이도(Heart rate variability; HRV)를 통해 확인하고자 하였다.

\section{연구 방법}

\section{연구 대상}

본 연구의 선정기준은 $\mathrm{S}$ 대학에 재학중인 학생 중 1) 최소 19 세 이상인 성인 남녀, 2) 지난 3 개월 동안 경추 교정을 받은 적이 없는 자로 정하였다. 기간은 선행 연구 에 의해 척추 교정 효과가 3 개월간 지속될 수 있다는 근 거로 정해졌다[22]. 제외 기준은 다음과 같이 정하였으며 실험전 질문을 통해 해당하는 경우 제외시켰다. 1) 경추의 수술 이력, 2) 골절 혹은 탈골, 3) 경추의 비정상적인 해 부학적 구조, 4) 3 개월 이내의 경추 외상 혹은 그 전의 외 상으로 인한 후유증, 5) 암 병력, 6) 체위성 현기, 7) 스테 로이드 치료 혹은 항응고제 복용, 8) 만성 재발성 염증 질 환, 9) 척추 손상[23].

모든 대상자에게 본 연구의 목적을 설명하고 연구 참여 에 동의한 대상자만을 참여시켰다. 모든 진행은 헬싱키선 언에 따라 윤리 기준을 준수하였다. 중재 후 즉각적인 변 화를 측정하였다.

\section{연구 절차}

본 연구는 사전사후 통제집단설계를 통해 상부경추 교 정군(UCM group)과 목 스트레칭군(NS group)으로 나누 어 진행하였다. 참여자 모집은 $\mathrm{SNS}$ 를 통해 2주간 모집 공고를 하였으며 참여의사를 밝힌 사람을 참여시켰다. 참 여자는 난수표를 이용하여 교대로 실험군(집단1)과 대조 군(집단2)으로 무작위로 할당하여 배정하였다.
$\mathrm{UCM}$ 군은 편안한 의자에 앉아 $\mathrm{HRV}$ 를 측정한 후, 바 로 교정 테이블에 누워 치료사에 의해 상부경추 교정을 받았다. 교정 후 다시 측정을 위한 의자에 앉아 3 분간 휴 식을 취하고 $\mathrm{HRV}$ 를 재 측정하였다. $\mathrm{NS}$ 군은 $\mathrm{HRV}$ 사전 측정 후 그 자리에서 스트레칭을 시행하고, 3 분간의 휴식 을 취한 후 사후 측정을 하였다.

\section{중재 방법}

\section{상부 경추 교정}

상부 경추 교정은 숙련된 치료사에 의해 진행되었으며, 참여자를 테이블에 바로 눕히고 환추를 촉진하여 가동성 (mobility)을 검사하고 가동성이 떨어지는 쪽의 환추의 후 궁(posterior arch) 혹은 관절주(articular pillar)를 검지로 컨택하여 고속저진폭의 교정을 1 회 시행하여 교정음이 발 생하도록 하였다. 교정음이 들리지 않을 경우 1 회 더 시 도하였고 그 이후에는 교정이 된 것으로 간주하였다 (Figure 1)[23].

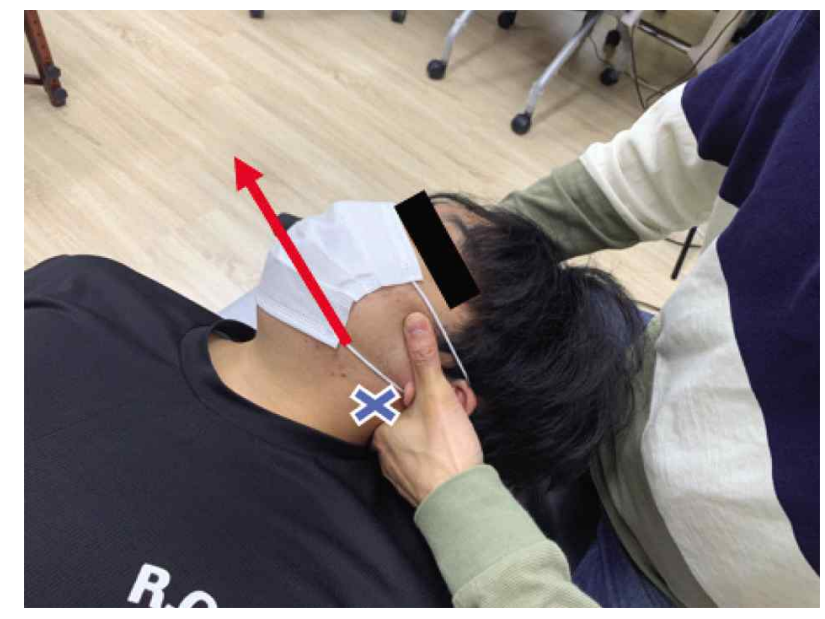

Figure 1. Upper Cervical Manipulation. Red arrow indicates line of drive. Blue $\mathrm{X}$ indicates the segmental contact point (posterior arch of $\mathrm{C} 1$ ).

\section{스트레충'}

대조군에게는 앉은 자리에서 양측 상부 승모근과 견갑 거근을 스트레칭 하도록 하였다. 상부 승모근의 스트레칭 을 위해서 참가자는 목을 가쪽으로 굽히고 반대쪽 손으로 약하게 당긴다. 같은 쪽 어깨가 따라오는 것을 방지하기 위해 손을 엉덩이 아래에 놓도록 지시하였다. 견갑거근의 스트레칭을 위해서는 신장시키고자 하는 반대쪽으로 회전 하고 머리를 굴곡한 후 손을 머리에 올려 살짝 당긴다. 어 깨가 따라오는 것을 방지하기 위해 손을 엉덩이 아래에 


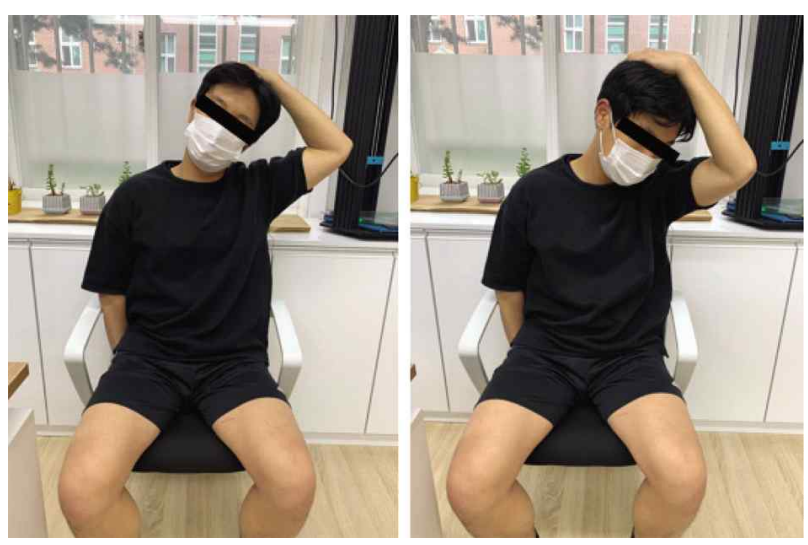

Figure 2. Stretching of Upper Trapezius and Levator Scapular

놓도록 지시하였다[24]. 스트레칭 자세에서 8초간 유지하 도록 하였다(Figure 2).

\section{측정방법 및 도구}

\section{심복변이도(Heart Rate Variability; HRV)}

$\mathrm{HRV}$ 를 측정하기 위해 자율신경 검사기 $(\mathrm{SA}-3000 \mathrm{NEW}$, MEDICORE CO., Korea)를 사용하였다. 이 장비는 모세 혈관의 맥파와 자율신경계와 관련된 생체 신호 정보를 측 정하여 혈관 관련 지표와 스트레스 관련 지수를 파악할 수 있는 장비로써 사용되고 있다[25]. 조용하고 일정한 온 도 $\left(20-25^{\circ} \mathrm{C}\right)$ 가 유지되는 공간에 참가자가 도착하면 의자 에 앉아 10 분간 휴식을 취하게 한 후 실험을 시작하였다. 실험에 참여하기 전 과도한 운동, 흡연 및 커피 섭취를 금 지시켰으며 실험이 진행되는 동안 필요한 경우를 제외하 고 말을 하지 않도록 지시하였다. $\mathrm{HRV}$ 측정 중에는 눈을 감거나 움직이지 않도록 하였다. 편안한 상태로 의자에 앉은 후 세 개의 전극을 참가자의 양쪽 팔목과 오른쪽 다 리에 각각 붙였다(Figure 3).

$\mathrm{HRV}$ 는 심리적, 신체 내부, 혹은 외부 환경의 자극에 따라 자율 신경계의 영향으로 변화하는 심박수의 변화를 의미한다[26]. 이 변화의 분석을 통해 심장의 건강과 심장 활동을 조절하고 변화하도록 하는 자율신경계의 상태를 평가할 수 있는데[27], 특히, 시간 영역분석(Time Domain Analysis)을 이용하여 HRV 임상변수인 자율신경 활성도 (Autonomic Activity), 자율신경 균형도(Autonomic Balance), 스트레스 저항도(Stress Index), 피로도(Fatigue Index)를 측정하였다. 자율신경 활성도는 90-110을 정상 범위로 하 고 $\mathrm{TP}, \mathrm{SDNN}$ 을 반영한 값이다. 건강한 상태일수록 더 높은 점수가 나타난다. 자율신경 균형도는 0-50을 정상범 위로 하고 $\mathrm{LF} / \mathrm{HF}$ ratio를 반영한 값으로 점수가 높을수록 조절능력이 떨어지는 것을 의미한다. 스트레스 저항도는

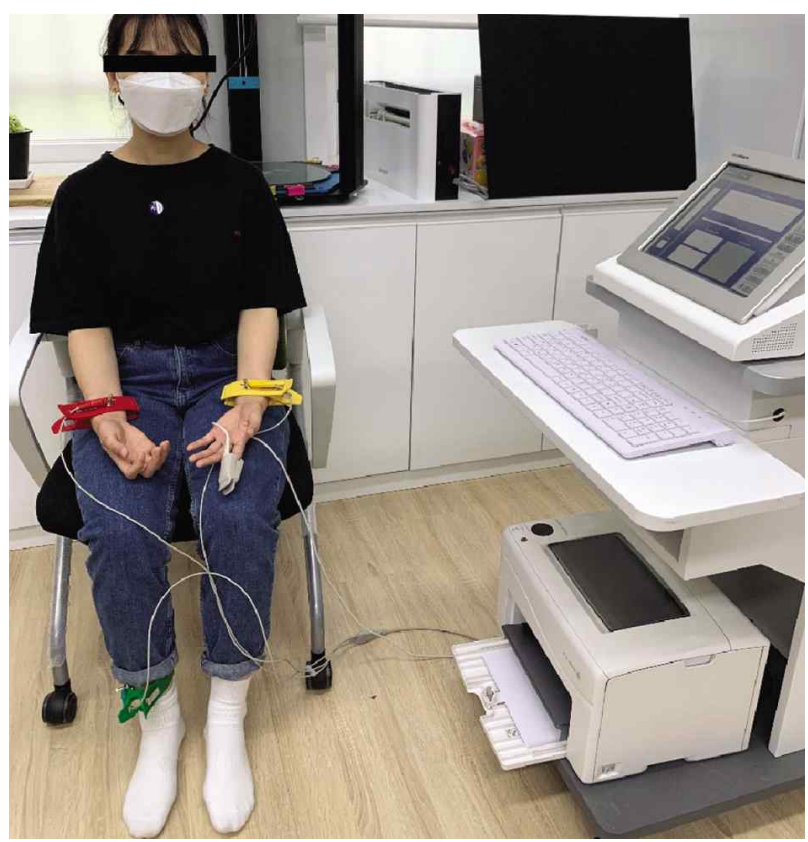

Figure 3. Electrode Placement

90-110이 정상범위이며 SDNN을 반영한 수치로 높은 점 수일수록 건강한 상태를 의미한다. 스트레스 지수는 HRV 와 심박수를 통해 얻어진 값이며 90-110을 정상 범위로 하고 낮은 점수일수록 건강한 상태를 나타낸다. 피로도는 $\mathrm{TP}, \mathrm{LF}$, 스트레스 지수를 통해 얻어진 값으로 스트레스 지수와 같은 정상 범위를 갖고 낮은 점수일수록 건강한 상태를 의미한다[28].

\section{자료 분석}

본 연구의 모든 자료의 통계분석은 SPSS(ver. 19, IBM Co., USA)를 이용하였다. 자료는 Shapiro-Wilk 검정에 의한 정규성 검정을 하였고, 평균과 표준편차를 산출하였 다. 정규성 검정 후 정규분포 가정을 만족하여 대상자의 인구 사회학적 특성은 실수와 백분율, 평균과 표준편차로 분석하였으며, 군간 동질성 검정을 위해 독립표본 $\mathrm{t}$ 검정 과 카이제곱 검정을 사용하였다. 중재 전·후 종속변수의 변화는 대응표본 $\mathrm{t}$ 검정으로 분석하였으며, 군간 효과를 비교하기 위해 독립표본 $\mathrm{t}$ 검정을 사용하였다. 자료의 모 든 통계적 유의수준 $(\alpha)$ 은 0.05 로 설정하였다.

\section{연구결과}

\section{연구 대상자의 일반적 특성}

본 연구에 참여한 $\mathrm{UCM}$ 군과 $\mathrm{NS}$ 군의 일반적 특성은 다음의 표와 같으며, 성별, 나이, 키, 몸무게 등에서 동질 성을 확인할 수 있었다(Table 1). 
Table 1. General Characteristics of Participants

\begin{tabular}{lllll}
\hline & UCM group $(\mathbf{n}=\mathbf{1 7})$ & NS group $(\mathbf{n}=\mathbf{1 7})$ & $\chi^{2} / t$ & $\mathbf{p}$ \\
\hline Age $($ years) & $23.24(2.59)$ & $23.29(2.11)$ & 0.073 & 0.943 \\
Height $(\mathrm{cm})$ & $169.91(8.63)$ & $167.06(9.30)$ & 0.927 & 0.361 \\
Weight $(\mathrm{kg})$ & $63.94(8.75)$ & $63.00(15.38)$ & 0.219 & 0.828 \\
\hline
\end{tabular}

The values are presented mean (SD)

UCM: upper cervical manipulation, NS: neck stretching.

\section{자율신경계 활동의 변화}

심박변이도를 통해 알아본 자율신경계 활동에 대한 그 룹 내 변화에서는 NS 군은 유의한 차이가 나타나지 않은 반면, UCM 그룹이 전-후 비교에서 자율신경 활성도, 스
트레스 저항도, 스트레스 지수, 피로도에서 유의한 차이를 보였다 $(\mathrm{p}<0.05)$. 그룹 간 전-후의 변화량 비교에서는 UCM 군이 NS군에 비해 자율신경 활성도, 스트레스 저항도, 피 로도에서 유의한 차이를 나타냈다 $(\mathrm{p}<0.05)($ Table 2).

Table 2. The alteration of ANS

$(n=34)$

\begin{tabular}{|c|c|c|c|c|c|}
\hline & & UCM group $(n=17)$ & NS group $(n=17)$ & $\mathbf{t}$ & $\mathbf{p}$ \\
\hline \multirow{5}{*}{$\begin{array}{l}\text { ANS Activity } \\
\text { (Score) }\end{array}$} & Pre & $89.58(22.04)$ & $98.87(21.14)$ & 1.255 & 0.219 \\
\hline & Post & $104.01(12.88)$ & $97.29(19.17)$ & & \\
\hline & Pre-Post & $14.43(16.92)$ & $-1.58(10.65)$ & 3.301 & 0.000 \\
\hline & $\mathrm{t}$ & 3.515 & 0.611 & & \\
\hline & $\mathrm{p}$ & 0.003 & 0.550 & & \\
\hline \multirow{5}{*}{$\begin{array}{l}\text { ANS Balance } \\
\text { (Score) }\end{array}$} & Pre & $82.32(38.97)$ & $87.48(42.70)$ & 0.368 & 0.715 \\
\hline & Post & $91.82(37.01)$ & $60.08(49.67)$ & & \\
\hline & Pre-Post & $9.50(62.75)$ & $-27.41(59.71)$ & 1.757 & 0.089 \\
\hline & $\mathrm{t}$ & 0.624 & 1.901 & & \\
\hline & $\mathrm{p}$ & 0.541 & 0.077 & & \\
\hline \multirow{5}{*}{$\begin{array}{l}\text { Stress Resistance } \\
\text { (Score) }\end{array}$} & Pre & $86.29(17.96)$ & $97.65(22.87)$ & 1.610 & 0.117 \\
\hline & Post & $96.24(17.56)$ & $95.82(21.32)$ & & \\
\hline & Pre-Post & $9.94(17.14)$ & $-1.82(7.59)$ & 2.588 & 0.014 \\
\hline & $\mathrm{t}$ & 2.392 & 0.992 & & \\
\hline & $\mathrm{p}$ & 0.029 & 0.337 & & \\
\hline \multirow{5}{*}{$\begin{array}{l}\text { Stress Index } \\
\text { (Score) }\end{array}$} & Pre & $105.41(11.44)$ & $102.94(14.10)$ & 0.561 & 0.579 \\
\hline & Post & $100.41(9.51)$ & $102.41(15.60)$ & & \\
\hline & Pre-Post & $-5.00(8.78)$ & $-0.53(7.33)$ & 1.611 & 0.117 \\
\hline & $\mathrm{t}$ & 2.347 & 0.298 & & \\
\hline & $\mathrm{p}$ & 0.032 & 0.770 & & \\
\hline \multirow{5}{*}{$\begin{array}{l}\text { Fatigue Index } \\
\text { (Score) }\end{array}$} & Pre & $107.57(17.15)$ & $96.27(20.57)$ & 1.740 & 0.092 \\
\hline & Post & $99.22(13.56)$ & $99.06(15.60)$ & & \\
\hline & Pre-Post & $-8.35(16.11)$ & $2.79(14.76)$ & 2.102 & 0.043 \\
\hline & $\mathrm{t}$ & 2.137 & 0.780 & & \\
\hline & $\mathrm{p}$ & 0.048 & 0.447 & & \\
\hline
\end{tabular}

The values are presented mean (SD)

ANS: autonomic nervous system, UCM: upper cervical manipulation, NS: neck stretching. 


\section{고찰}

본 연구는 상부경추 교정이 자율신경계의 활동에 미치 는 영향을 알아보고자 시행되었다.

척추 교정은 다양한 근골격계 문제를 해결하는데 널리 사용되고 있으며 이러한 문제 해결을 위해 가동술과 교정 술 등 다양한 척추교정 방법이 발전되어 왔다[29]. 척추교 정을 통해 얻고자 한 주된 목적은 통증 감소와 척추 부정 렬의 교정이었다[1]. 또한, 선행 연구를 통해 근골격계 증 상들 이외에도 스트레스, 불안과 우울감과 같은 정신신체 (psychosomatic) 증상들이 척추의 부정렬과 매우 관련이 깊다고 밝혀졌다[30]. 그러나 아직까지 상부경추 교정이 자율신경계 활동에 미치는 영향에 대한 연구는 부족한 실 정이다. 경추에 가해진 교정에 대한 효과를 보기 위한 선 행연구에서는 혈압[31], 심장 자율신경계 활동[32], 피부 온도[33], 피부 전도도[34], 말초 혈류 변화[35] 등의 변 화를 주로 측정하였다.

본 연구에서는 상부경추 교정의 효과를 알아보기 위해 자율신경계의 활동 변화를 측정할 수 있는 $\mathrm{HRV}$ 를 이용 하였다. HRV는 심장주기와 다음 주기 사이의 미세한 변 화를 말하는데, 심장 박동에 영향을 주는 동방결절 즉 전 기 자극 형성 부위에 자율신경계가 어떻게 영향을 미치는 지 교감신경과 부교감신경의 상호 작용을 파악할 수 있기 때문이다[25].

경추 교정이 어떻게 원격 효과를 일으키는지에 대한 이 해는 아직 완전하지 못하나, 자율신경계를 자극함으로 인 해, 특히 교감신경계를 자극하여 효과를 가져온다고 가정 하고 있다 $[32,33,35,36]$ 이 결과는 $\mathrm{UCM}$ 군이 직접적 으로 목 주변 조직의 수용기에 대한 자극이 컸기 때문으 로 여겨진다. 이는 Budgell과 Hirano[17]의 연구에서와 마찬가지로 상부경추의 고속저진폭 교정은 전정기관을 자 극하였을 것이고, 이는 곧 교감신경 활동에 영향을 미쳤 기 때문으로 생각된다. 또한, 경추에 가해지는 고속저진폭 교정은 경추의 빠른 움직임을 만들면서 교정음을 발생시 킨다. 이 교정음은 교정 중에 관절이 부드럽게 견인될 때 활액에 용해된 가스의 공동현상(cavitation)으로 인해 터 지는 소리로 여겨지고 있다. 이는 대상자들에게 실제로 교정이 되었다고 하는 확인을 주어 심리적인 효과를 가져 오고 이것이 생리적인 효과로 관찰되는 것으로 여겨진다. 실제로 이 실험에 참여한 대상자들은 교정 후에 근육 톤 이 감소하여 느끼는 편안함을 느꼈으며 이는 생리학적인 변화와 심리적인 변화가 교감신경의 활동을 감소시킨 것 으로 여겨진다고 보고하였다[23, 37]. 본 실험의 결과에서 도 $\mathrm{UCM}$ 군은 $\mathrm{NS}$ 군에 비해 자율신경 활성도, 스트레스 저항도, 피로도가 유의한 변화를 나타냈다 $(\mathrm{p}<0.05)$.

상부경추 뿐 아니라 다른 부위의 척추 교정을 통해 자
율신경계의 변화를 본 선행 연구는 다수가 있다. 그 중 Budgell[32]의 연구에서는 흥추 교정이 자율신경계에 미 치는 영향을 연구하였으며,이 연구에서 sham 그룹보다 자 율신경계 자극에 더 효과가 있다고 나타났다. 또한, Park 등[32]의 연구에서는 골반 교정이 폐경기 여성의 HRV에 미치는 효과를 연구하였으며, 이 연구에서는 sham 그룹에 비해 통증이 유의하게 감소하고 자율신경계의 활동에 효 과가 있다고 나타났다. 경추 교정에서도 상부경추가 아닌 C2-C5까지 교정을 한 후 자율신경계의 변화를 측정한 연 구도 있었으며 결과에서도 유의한 변화를 확인할 수 있었 다[18].

척추 교정이 정신적인 요소들에 미치는 영향에 대한 연 구는 아쉽게도 매우 부족한 상황이지만[21], 몇몇 연구에 서 척추 교정 후에 혈액 검사를 통해 생화학적 지표들의 변화를 연구하여 스트레스 반응에 대한 연구를 진행하였 다. 특히, 경추교정 후에 스트레스 요인에 저항하도록 돕 는 인체의 스트레스 반응을 조절하는 코티솔(Cortisol)이 증가되었음을 확인할 수 있었다[38, 39]. 본 연구에서도 생화학적 지표들의 변화를 측정하지는 못했지만, HRV 임 상 지표인 스트레스 저항도가 실험 전후 그리고 군간 비 교에서도 유의하게 증가함을 확인할 수 있었다 $(\mathrm{p}<0.05)$.

본 연구의 제한점으로는 적은 수의 건강한 실험 참가자 로 실험 결과를 일반화하기 어려움이 있고, $\mathrm{UCM}$ 군에서 움직임이 제한된 부위를 찾기 위한 촉진에서 경추를 자극 하여 정확하게 교정으로 인한 자극만을 주었다고 말하기 어렵다는 것이다. 또한, 대조군에게 적용한 목 스트레칭이 상부경추 교정과 비교할 수 있는지에 대한 명확한 근거가 없다는 것이다. 앞으로는 이러한 제한점을 보완하여 더 많은 연구가 이루어져야 할 것으로 생각된다.

\section{결론}

자율신경계 활동을 증가시키기 위한 방법으로 상부경 추 교정이 효과가 있음이 나타났다. 이를 바탕으로 자율 신경계 활동을 변화시켜 스트레스 저항도와 피로도, 자율 신경계 활성을 변화시킬 목적으로 상부경추 교정이 사용 될 수 있을 것으로 생각된다.

\section{이해 충돌}

본 연구의 저자들은 연구, 저작권, 및 출판과 관련하여 잠재적인 이해충돌이 없음을 선언합니다.

\section{참고문헌}

1. Bialosky JE, Simon CB, Bishop MD, George SZ. 
Basis for spinal manipulative therapy: a physical therapist perspective. J Electromyogr Kinesiol. 2012;22:643-7.

2. Gopal Nambi S, Vora PK, Jhang M. Cervical spine mobilization versus Thoracic spine manipulation in subjects with unilateral C6 and C7 Cervical Radiculopathy. 2016;22.

3. Kingston L, Claydon L, Tumilty S. The effects of spinal mobilizations on the sympathetic nervous system: a systematic review. Man Ther. 2014;19:281-7.

4. Krekoukias G, Gelalis ID, Xenakis T, Gioftsos G, Dimitriadis Z, Sakellari V. Spinal mobilization vs conventional physiotherapy in the management of chronic low back pain due to spinal disk degeneration: a randomized controlled trial. J Man Manip Ther. 2017;25:66-73.

5. Sillevis R, Cleland J, Hellman M, Beekhuizen K. Immediate effects of a thoracic spine thrust manipulation on the autonomic nervous system: a randomized clinical trial. J Man Manip Ther. 2010;18:181-90.

6. Manchikanti L, Singh V, Datta S, Cohen SP, Hirsch JA, American Society of Interventional Pain P. Comprehensive review of epidemiology, scope, and impact of spinal pain. Pain Physician. 2009;12:E35-70.

7. Gross A, Miller J, D'Sylva J, Burnie SJ, Goldsmith $\mathrm{CH}$, Graham N, et al. Manipulation or mobilisation for neck pain: a Cochrane Review. Man Ther. 2010;15:315-33.

8. Lystad RP, Bell G, Bonnevie-Svendsen M, Carter CV. Manual therapy with and without vestibular rehabilitation for cervicogenic dizziness: a systematic review. Chiropr Man Therap. 2011;19:21.

9. Chaibi A, Russell MB. Manual therapies for cervicogenic headache: a systematic review. J Headache Pain. 2012;13:351-9.

10. Bialosky JE, George SZ, Horn ME, Price DD, Staud R, Robinson ME. Spinal manipulative therapy-specific changes in pain sensitivity in individuals with low back pain (NCT01168999). J Pain. 2014;15:136-48.

11. Delitto A, George SZ, Van Dillen L, Whitman JM, Sowa G, Shekelle P, et al. Low back pain. J Orthop Sports Phys Ther. 2012;42:A1-57.
12. Araujo FX, Ferreira GE, Angellos RF, Stieven FF, Plentz RDM, Silva MF. Autonomic Effects of Spinal Manipulative Therapy: Systematic Review of Randomized Controlled Trials. J Manipulative Physiol Ther. 2019;42:623-34.

13. La Touche R, Paris-Alemany A, Mannheimer JS, Angulo-Diaz-Parreno S, Bishop MD, Lopez-Valverde-Centeno A, et al. Does mobilization of the upper cervical spine affect pain sensitivity and autonomic nervous system function in patients with cervico-craniofacial pain?: A randomized-controlled trial. Clin J Pain. 2013;29:205-15.

14. Wright A. Hypoalgesia post-manipulative therapy: a review of a potential neurophysiological mechanism. Man Ther. 1995;1:11-6.

15. Bakris G, Dickholtz M, Sr., Meyer PM, Kravitz G, Avery E, Miller M, et al. Atlas vertebra realignment and achievement of arterial pressure goal in hypertensive patients: a pilot study. J Hum Hypertens. 2007;21:347-52.

16. Ward J, Tyer K, Coats J, Williams G, Weigand S, Cockburn D. Immediate effects of atlas manipulation on cardiovascular physiology. Clinical Chiropractic. 2012;15:147-57.

17. Galaasen Bakken A, Axen I, Eklund A, O'Neill S. The effect of spinal manipulative therapy on heart rate variability and pain in patients with chronic neck pain: a randomized controlled trial. Trials. 2019;20:590.

18. Cui K-m, Li W-m, Liu X, Brian B, Li N, Wu G-c. Effect of cervical manipulation on autonomic nervous function in healthy volunteers. Journal of Acupuncture and Tuina Science. 2006;4:267-70.

19. Puhl AA, Injeyan HS. Short-term effects of manipulation to the upper thoracic spine of asymptomatic subjects on plasma concentrations of epinephrine and norepinephrine-a randomized and controlled observational study. J Manipulative Physiol Ther. 2012;35:209-15.

20. Perry J, Green A, Singh S, Watson P. A preliminary investigation into the magnitude of effect of lumbar extension exercises and a segmental rotatory manipulation on sympathetic nervous system activity. Man Ther. 2011;16:190-5.

21. Alansari SM, Youssef EF, Shanb AA. Efficacy of 
manual therapy on psychological status and pain in patients with neck pain. A randomized clinical trial. Saudi Med J. 2021;42:82-90.

22. Furlan AD, Yazdi F, Tsertsvadze A, Gross A, Van Tulder M, Santaguida L, et al. A systematic review and meta-analysis of efficacy, cost-effectiveness, and safety of selected complementary and alternative medicine for neck and low-back pain. Evid Based Complement Alternat Med. 2012;2012:953139.

23. Budgell B, Hirano F. Innocuous mechanical stimulation of the neck and alterations in heart-rate variability in healthy young adults. Auton Neurosci. 2001;91:96-9.

24. Carnes MA, Vizniak NA. Quick reference evidence-based conditions manual. British Columbia, Canada: Professional Health Systems Inc.; 2010.

25. Lee J. A Comparison between Effects of Lavender Essential Oil and Artificial Lavender Oil Inhalation on Stress, HRV, and Blood Pressure in Adults. Pocheon: CHA universitiy; 2020.

26. Rajendra Acharya U, Paul Joseph K, Kannathal N, Lim CM, Suri JS. Heart rate variability: a review. Med Biol Eng Comput. 2006;44:1031-51.

27. Kim SM, Kim DJ, Choi BH. Report on the vaso-aging degree of workers by SA3000P. Kor J Ori Med Physiol Pathol. 2009;23:1178-82.

28. Lee JM, Park JH, Lee EJ, Jean TD, Hong SY. Effect of Chuna Treatment (Manipulation) on Lumbar Sprain caused by Traffic Accident in Early Stage.-by Analysis of the Heart Rate Variability (HRV) and Visual Analogue Scale (VAS). The Journal of Korea CHUNA Manual Medicine for Spine and Nerves. 2009;4:61-74.

29. Mintken PE, Derosa C, Little T, Smith B, American Academy of Orthopaedic Manual Physical T. A model for standardizing manipulation terminology in physical therapy practice. $\mathrm{J}$ Man Manip Ther. 2008;16:50-6.

30. Wirth B, Potthoff T, Rosser S, Humphreys BK, de Bruin ED. Physical risk factors for adolescent neck and mid back pain: a systematic review. Chiropr Man Therap. 2018;26:36.

31. Knutson GA. Significant changes in systolic blood pressure post vectored upper cervical adjustment vs resting control groups: a possible effect of the cervicosympathetic and/or pressor reflex. J Manipulative Physiol Ther. 2001;24:101-9.

32. Driscoll MD, Hall MJ. Effects of spinal manipulative therapy on autonomic activity and the cardiovascular system: a case study using the electrocardiogram and arterial tonometry. J Manipulative Physiol Ther. 2000;23:545-50.

33. Harris W, Wagnon RJ. The effects of chiropractic adjustments on distal skin temperature. J Manipulative Physiol Ther. 1987;10:57-60.

34. Chiu TW, Wright A. To compare the effects of different rates of application of a cervical mobilisation technique on sympathetic outflow to the upper limb in normal subjects. Man Ther. 1996;1:198-203.

35. Purdy WR, Frank JJ, Oliver B. Suboccipital dermatomyotomic stimulation and digital blood flow. J Am Osteopath Assoc. 1996;96:285-9.

36. Celander E, Koenig AJ, Celander DR. Effect of osteopathic manipulative therapy on autonomic tone as evidenced by blood pressure changes and activity of the fibrinolytic system. J Am Osteopath Assoc. 1968;67:1037-8.

37. Shafiq H, McGregor C, Murphy B. The impact of cervical manipulation on heart rate variability. Annu Int Conf IEEE Eng Med Biol Soc. 2014;2014:3406-9.

38. Plaza-Manzano G, Molina-Ortega F, Lomas-Vega R, Martinez-Amat A, Achalandabaso A, Hita-Contreras F. Changes in biochemical markers of pain perception and stress response after spinal manipulation. J Orthop Sports Phys Ther 2014;44:231-9.

39. Kovanur-Sampath K, Mani R, Cotter J, Gisselman AS, Tumilty S. Changes in biochemical markers following spinal manipulation-a systematic review and meta-analysis. Musculoskelet Sci Pract. 2017;29:120-31. 